\title{
Заключение
}

Для пленок стабилизированного титаната бария, полученных методом Ленгмюра-Блоджетт, толщиной 32, 128, 352 нмизмерены пьезомодуль и температура Кюри, которые составили 40 пм/В и 347 К; 14 пм/В и 352 К; 4.5 пм/В и 356 К соответственно. Для пленки толщиной 32 нмрассчитаны показатель преломления 1.96 , диэлектрическая проницаемость -61.5 , постоянная Кюри-Вейса $-\mathrm{C} \approx 3.103 \mathrm{~K}$.

$$
* * *
$$

1. Paniagua S.A., Kim Y., Henry K. Surface-Initiated Polymerization from Barium Titanate Nanoparticles for Hybrid Dielectric Capacitors. Applied materials and interfaces, 2014, Vol. 6, p. 3477 - 3482.

2. Cole M.W., Weiss C.V., Ngo E., Hirsch S., Coryell L.A., Alpay S.P. Microwave dielectric properties of graded barium strontium titanate films. Appl. Phys. Lett., 2008, Vol.92, p. 182906-1 - 182906-3.

3. A.S. Sizov, O. Yacovlev et al. A.P. Kuzmenko Formation of Spherical Nanoparticles BaTiO3 by Peroxide Method. Journal of Nano- and Electronic Physics, №5, 2013, p. 04024-1 - 04024-2

4. Kuzmenko A.P., Chuhaeva I.V., Abakumov P.V. et al. An Analysis of the Deposition Process and the Structure of Ferroelectric Langmuir Films of Barium Titanate. Journal of Nano- and Electronic Physics,2015, Vol. 7,No 4, p. 04025-1 $\square$ 04025-4.

5. Liang D., Stone D. S., Lakes R. S. Enhanced dielectric and piezoelectric properties of $x B a Z r O 3-$ (12x)BaTiO3 ceramics. Journal of Applied Physics, 2012, Vol. 111, p. 084107-1 - 084107-10.

6. Зубко С.П. Модель размерного эффекта в тонкой сегнетоэлектрической пленке в условиях фазового перехода. ФТТ, 2010, Т. 52, Вып. 12, с. $2401-2404$.

7. L. M. Eng, T. Otto H. Chaib Dielectric polarization and refractive indices of ultrathin barium titanate films on strontium titanate single crystals // Journal of Physics: Condensed Matter. — №17. — 2005. — c. 161 179.

8. N.A. Emelianov Structure and dielectric properties of composite material based on surface-modified BaTiO3 nanoparticles in polysterene. European Physical Journal Applied Physics, 2015, 69, p. 10401 10406.

\section{Савинов К.Н. \\ Особенности режимов генерации полупроводникового лазера с внешним резонатором при свч модуляции}

Новосибирский государственный технический университет (Росиия, Новосибирск)

doi:10.18411/spc-12-11-2017-03

idsp: 000001:spc-12-11-2017-03

\section{Аннотация}

При модуляции тока накачки полупроводникового лазера ( $\lambda=795$ нм) наблюдалась осциллирующая зависимость амплитуд боковых составляющих от СВЧ частоты и найдена связь этих осцилляций со структурой поля в резонаторе лазера.

Ключевые слова: рубидиевый стандарт частоты, полупроводниковый лазер, накачка стандарта частоты, частотная модуляция.

\section{Abstract}

When the pumping current of a semiconductor laser $(\lambda=795 \mathrm{~nm})$ was modulated, the oscillating dependence of the side components amplitudes due to the microwave frequency was observed, and the coupling of this dependence with the field structure in the laser cavity was found.

\section{Введение}

Разработка квантовых стандартов частоты (КСЧ) радиодиапазона является одним из важнейших направлений в измерительной технике, так как они нашли широкое применение во многих областях (навигация, прецизионные измерения и т.д.). Среди КСЧ радиодиапазона наиболее массовыми являются рубидиевые стандарты частоты (РСЧ). В настоящее время существует потребность в повышении 
метрологических характеристик РСЧ. Одним из решений данной задачи является использование лазерного излучения в качестве оптической накачки.

Наиболее перспективным методом, на наш взгляд, является использование для накачки стандарта полупроводникового лазера с шириной линии порядка 10 кГц. При подобной накачке становится возможным создание стандарта частоты способного работать как в оптическом, так и в СВЧ диапазоне. Вклад в накачку в этом случае вносят только боковые СВЧ компоненты спектра, отстоящие друг от друга на частоту часового перехода. Для эффективной накачки необходимо было определить зависимость амплитуды боковых составляющих от частоты СВЧ модуляции.

\section{Блок-схема экспериментальной установки}

Схема измерения спектра излучения лазера представлена на рис.1.

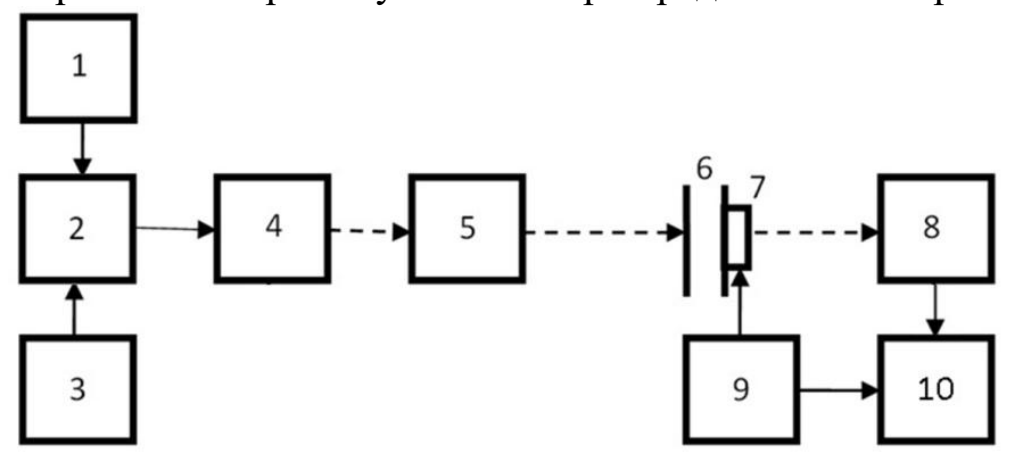

Рис.1. Схема измерений спектра излучения лазера: 1 - блок питания лазера; 2 - смеситель; 3 - СВЧ генератор; 4 - полупроводниковый лазер; 5 - оптический изолятор; 6-интерферометр Фабри-Перо; 7

- пьезокерамика; 8- фотодетектор; 9 -генератор пилообразного напряжения; 10 - ичифровой осичиллограф.

Сигналы от блока питания постоянным током (1) и от СВЧ генератора (3) через смеситель (2) поступали на диодный лазер (4). Излучение лазера для устранения обратной связи пропускалось через оптический изолятор (5) и направлялось на интерферометр Фабри-Перо (6). Выходное зеркало крепилось на пьезокерамике (7), которая сканировала длину (частоту) интерферометра с помощью цифрового генератора пилообразного напряжения (9). Прошедшее через интерферометр излучение регистрировалось фотодетектором (8), сигнал с выхода которого поступал на цифровой осциллограф (10). Для синхронизации развертки осциллографа с перестройкой длины (частоты) интерферометра на его второй канал поступал сигнал от генератора пилообразного напряжения.

\section{Экспериментальные результаты и их обсуждение}

В результате нами была получена зависимость амплитуды боковых составляющих от частоты СВЧ-накачки, которая имела осциллирующий вид (рис.2.).

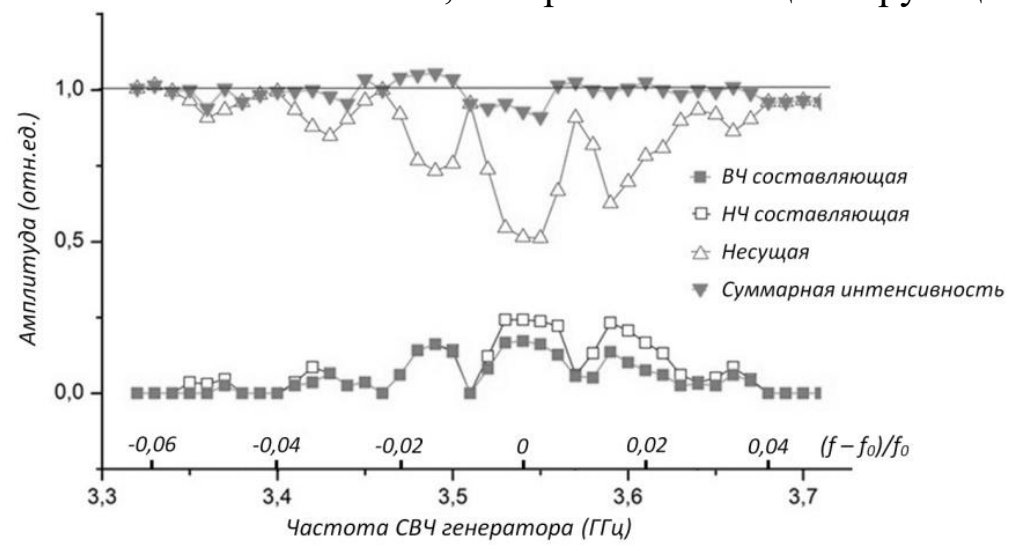

Рис.2. Зависимость амплитуд боковых составляющих, несущей и суммарной интенсивности от частоты модуляции. 
Необходимо было выяснить причины подобного поведения зависимости.

Было выдвинуто предположение, что осцилляции связаны с некоторой структурой волнового фронта излучения. Для проверки гипотезы необходимо было получить данные о пространственном распределении интенсивности излучения. На расстоянии 899 мм от источника излучения распределение имело следующий вид (рис.3a).

Видно, что в горизонтальном профиле имеет место некоторая структура. Можно заметить сходство данной структуры с видом зависимости амплитуды боковых составляющих от частоты модуляции (рис.3б). Это позволяет сделать вывод о связи структуры волнового фронта излучения с осцилляциями зависимости амплитуды боковых составляющих от частоты модуляции.
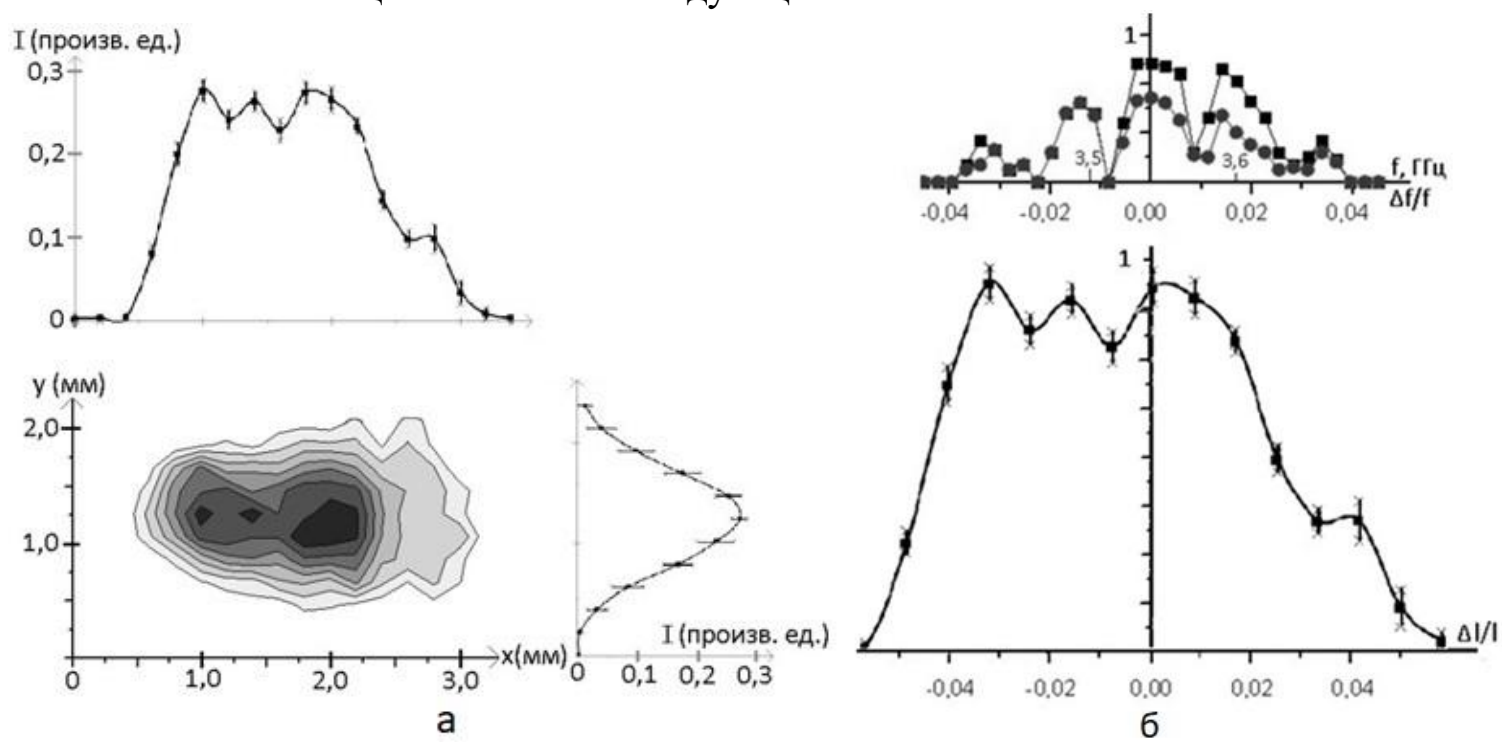

Рис.3. Сечение излучения и его профили на расстоянии 899 мм от источника (а), сравнение структурь волнового фронта и исследуемой зависимости (б).

\section{Заключение}

В представленной работе наблюдалась осциллирующая зависимость амплитуд боковых составляющих от частоты СВЧ подкачки. Такая зависимость связана со структурой волнового фронта. Наличие данной структуры, по-видимому, обусловлено использованием сложного составного резонатора лазера.

$$
* * *
$$

1. Григорьянц В. В., Жаботинский М. Е., Золин В. Ф., Квантовые стандарты частоты, Москва, 1968.

2. Багаев С. Н., Волков В. Г., Ивашко Д.Ю., Матюгин Ю. А., Фатеев Н. В. // Квантовая электроника, 1999, 26 (2), С.109-113.

3. Исакова А.А., Дмитриев А.К., Бикмухаметов К.А, Величанский В.Л., Васильев В.В., Зибров С.А. // Труды XII международной конференции АПЭП-2014, с.17-19. 